\title{
The clinical pathology of heart failure and atrial fibrillation in old age
}

\author{
H. M. HODKINSON \\ D.M., F.R.C.P. \\ Ariela Pomerance \\ M.D., M.R.C.Path.

\begin{abstract}
Departments of Geriatric Medicine and Histopathology, Northwick Park Hospital, Harrow, Middlesex
\end{abstract}

\begin{abstract}
Summary
The factors associated with the development of heart failure and of atrial fibrillation in elderly patients were studied in a prospective clinico-pathological series of 171 cases. Multiple logistic analyses allowed the contributions of multiple factors to be assessed simultaneously.

Senile cardiac amyloidosis, ischaemic heart disease and atrial fibrillation were significantly associated with heart failure and had additive effects. Senile cardiac amyloidosis, ischaemic heart disease, mitral valve ballooning and higher age were significantly associated with atrial fibrillation but their additive effects were modified by significant interactions between ischaemic heart disease and mitral valve ballooning (whose effects were multiplicative) and senile cardiac amyloidosis and age (the age effect being confined to those without amyloidosis).
\end{abstract}

\section{Introduction}

Heart failure is a common and important condition in old age. Ischaemic heart disease has generally been assumed to be the main cause. However, Pomerance (1965) in an extensive systematic study showed that, although an important cause, ischaemic heart disease accounted for less that $50 \%$ of cases of heart failure. Her most striking finding was that elderly patients with heart failure had a multiplicity of pathological findings which made the assessment of the cause very difficult.

Atrial fibrillation is also common in the elderly and similarly appears to have a variety of causes (Davies, 1976). It is considered as playing an important role in the development of heart failure in elderly patients (Caird, 1976).

With the present study it was sought to elucidate the multifactorial basis of heart failure and atrial fibrillation and their interrelationship in a prospective clinico-pathological study of the elderly.

\section{Patients and methods}

The study was part of a larger prospective investigation of heart disease of the elderly based on

Present address: Department of Medicine, Royal Postgraduate Medical School, Hammersmith Hospital, London W12. all patients admitted to the geriatric department of Northwick Park Hospital who were examined post mortem during the study period 1971-1975. The present series comprises 164 patients for whom a technically satisfactory ECG record was available in addition to full clinical records and detailed postmortem examination of the heart carried out by one pathologist (A.P.) using methods described elsewhere (Denham, Pomerance and Hodkinson, 1977; Hodkinson and Pomerance, 1977). In particular, this included a careful search for cardiac amyloidosis (Hodkinson and Pomerance, 1977).

Statistical analysis utilized a standard method of multiple logistic analysis with maximum likelihood estimation (Nelder, 1975). This allows the significance of associations between the condition of interest and each of a combination of factors (e.g. sex or the presence or absence of a condition) and continuous variables (such as age or blood pressure) to be tested simultaneously.

Ischaemic heart disease was defined to include old and recent infarction and diffuse fibrosis associated with coronary artery stenosis. Amyloidosis comprised those with at least substantial atrial deposits (grades 2-5 of Hodkinson and Pomerance, 1977) but not those with only early atrial deposits. Heart failure was defined to include both congestive and left ventricular failure.

\section{Results}

All patients were more than 60 years old; $62 \%$ were women and the average age was 81 years.

\section{Heart failure}

Both diastolic and systolic blood pressure show significant correlations with cardiac failure $(P<0.05$ for each). However, in both cases lower not higher pressures are associated with heart failure! This suggests that the changed pressures are an effect of heart failure rather than a cause. In any event, blood pressure failed to exert a significant independent effect when combined with other significant factors, namely atrial fibrillation, ischaemic heart disease and amyloidosis. The multiple logistic analysis for these 3 factors is shown in Table 1 . Table 2 shows the details of the distribution of the presence of 
these 3 significant factors alone and in combination in those patients with and without heart failure. Only $19.7 \%$ of heart failure cases are not 'explained' by the presence of one or more of the 3 factors and it can be seen that, although there is a higher incidence of heart failure within all pathological categories, the excess is most striking where 2 or 3 pathologies occur together. Thus, the factors appear to have an additive effect in predisposing to heart failure. Sex, age, heart weight and all categories of aortic and mitral valve disease make no significant contribution to the prediction of heart failure when combined with the 3 significant factors (atrial fibrillation, cardiac amyloidosis and ischaemic heart disease). This was also true of left bundle branch block although this factor did show a borderline association when tested independently $(P<0 \cdot 1)$. However, there were only 14 cases of left bundle branch block of whom 9 had heart failure.

TABLE 1. Multiple logistic analysis of atrial fibrillation, cardiac amyloidosis and ischaemic heart disease against the presence of heart failure (164 cases)

\begin{tabular}{lccc}
\hline Factor & $\begin{array}{c}\text { Linear } \\
\text { coefficient (b) }\end{array}$ & s.e. (b) & $P<$ \\
\hline $\begin{array}{l}\text { Atrial } \\
\quad \text { fibrillation }\end{array}$ & 0.995 & 0.406 & 0.02 \\
$\begin{array}{l}\text { Cardiac } \\
\quad \text { amyloidosis }\end{array}$ & 0.883 & 0.389 & 0.025 \\
$\begin{array}{l}\text { Ischaemic } \\
\text { heart disease }\end{array}$ & 0.727 & 0.351 & 0.05 \\
\hline
\end{tabular}

\section{Atrial fibrillation}

Ischaemic heart disease, cardiac amyloidosis, mitral valve ballooning and age show independently significant associations with atrial fibrillation when combined in a multiple logistic analysis (Table 3). Heart weight, which seems more likely to be a consequence of atrial fibrillation rather than a possible cause (Hodkinson, Pomerance and Hodkinson, 1979), is significantly associated with atrial fibrillation when analysed alone but not when added to the above combination. Aortic valve disease, mitral ring calcification, post-inflammatory mitral valve disease, systolic and diastolic blood pressure and sex are not significantly associated with atrial fibrillation. The lack of an association with post-inflammatory mitral disease is somewhat surprising but this was the least prevalent category of valve abnormality (17 cases) and in only 2 cases was it of a severity considered likely to be of functional significance.

Table 4 shows the distribution of the presence of ischaemic heart disease, cardiac amyloidosis and mitral ballooning in patients with and without atrial fibrillation. The simple additive effects of factors predisposing to heart failure are not seen. Ischaemic heart disease and mitral ballooning occurring alone are not associated with atrial fibrillation although all the combinations of the 2 factors are positively associated with it. These findings suggest interactions between factors and all the possible interactions between ischaemic heart disease, cardiac amyloidosis, mitral ballooning and age have therefore been examined by further multiple logistic analyses. Only 2 interactions, those between age and cardiac amyloidosis and between ischaemic heart disease and mitral ballooning, are statistically significant. The relevant multiple logistic analysis is shown in Table 5. The form of the interaction between age and amyloidosis is that age strongly favours the presence of atrial fibrillation? in the absence of amyloidosis but has little effect in its presence. Mitral ballooning and ischaemic heart disease have negligible effects alone but powerfully favour atrial fibrillation when they occur together, i.e. their effects appear to be multiplicative rather than additive. The non-significance of other interaction terms in the analyses implies that factors in other combinations have simple additive effects.

\section{Discussion}

An intrinsic problem in any clinico-pathological series is that conditions with a low prevalence cannot be shown to have significant effects. For

TABLE 2. Distribution of pathological findings in patients with and without heart failure

\begin{tabular}{lcc}
\hline Factor present & $\begin{array}{c}\text { Patients with failure } \\
\text { number }(\%)\end{array}$ & $\begin{array}{c}\text { Patients without } \\
\text { number }(\%)\end{array}$ \\
\hline None & $14(19 \cdot 7)$ & $48(51 \cdot 6)$ \\
Atrial fibrillation (AF) & $4(5 \cdot 6)$ & $2(2 \cdot 2)$ \\
Ischaemic heart disease (IHD) & $17(23 \cdot 9)$ & $19(20 \cdot 4)$ \\
Cardiac amyloidosis (CA) & $9(12 \cdot 7)$ & $10(10 \cdot 8)$ \\
AF+ IHD & $8(11 \cdot 3)$ & $6(6 \cdot 5)$ \\
IHD+CA & $4(5 \cdot 6)$ & $3(3 \cdot 2)$ \\
AF+CA & $10(14 \cdot 1)$ & $4(4 \cdot 3)$ \\
AF + IHD+CA & $5(7 \cdot 0)$ & $1(1 \cdot 1)$ \\
Total & 71 & 93 \\
\hline
\end{tabular}


example, in this series of 164 patients, of whom 71 had heart failure, a significant result cannot be obtained unless there are 4 or more patients with a given condition and until there are 7 or more cases, all must have heart failure for the association to be statistically significant (Fisher's exact test). Even where a prevalence is fairly high, there may be too few sufficiently severe cases for an effect to be demonstrable. For example, although there were 17 patients with mitral chronic inflammatory disease, this was of minor degree in all but 2 so that the failure to find a significant association with atrial fibrillation is not surprising. One must accept the limitation that studies such as this cannot identify uncommon factors no matter how powerful their effects. Factors must be both common and reasonably powerful if their effects are to be shown to be statistically significant.

TABLE 3. Multiple logistic analysis of the presence of cardiac amyloidosis, ischaemic heart disease and mitral ballooning and age against the presence of atrial fibrillation (171 cases).

\begin{tabular}{lccc}
\hline Factor & $\begin{array}{c}\text { Linear } \\
\text { coefficient (b) }\end{array}$ & s.e. (b) & $P<$ \\
\hline $\begin{array}{l}\text { Cardiac } \\
\text { amyloidosis }\end{array}$ & 1.577 & 0.438 & 0.001 \\
$\begin{array}{l}\text { Ischaemic } \\
\text { heart disease }\end{array}$ & 1.009 & 0.437 & 0.02 \\
$\begin{array}{l}\text { Mitral } \\
\text { ballooning }\end{array}$ & 1.314 & 0.618 & 0.05 \\
$\begin{array}{l}\text { Age (years) } \\
\text { (yen) }\end{array}$ & 0.059 & 0.027 & 0.05 \\
\hline
\end{tabular}

Nevertheless, the multiple logistic analysis technique used in the present study, although it shares this unavoidable limitation, offers an appropriate method for the analysis of causes of heart failure and atrial fibrillation in old age as both have been thought likely to have a multifactorial basis (Pomerance, 1965; Davies, 1976). This study supports the view that both have a multiple aetiology. In the case of heart failure, atrial fibrillation and ischaemic heart disease and cardiac amyloidosis are shown to be the key factors. Atrial fibrillation and ischaemic heart disease are well recognized factors (Caird, 1976) and cardiac amyloidosis has also been shown to be an important cause of heart failure in old age (Hodkinson and Pomerance, 1977). However, the additive effects of these 3 factors have not been demonstrated previously.

TABLE 5. Multiple logistic analysis of cardiac amyloidosis, ischaemic heart disease, mitral ballooning, age and their significant interactions against atrial fibrillation (171 cases).

\begin{tabular}{lccc}
\hline Factor & $\begin{array}{c}\text { Linear } \\
\text { coefficient (b) }\end{array}$ & s.e. (b) & $P<$ \\
\hline $\begin{array}{l}\text { Cardiac } \\
\quad \text { amyloidosis }\end{array}$ & 13.090 & 5.020 & 0.01 \\
$\begin{array}{l}\text { Ischaemic } \\
\quad \text { heart disease }\end{array}$ & 2.029 & 0.777 & 0.01 \\
$\begin{array}{l}\text { Mitral } \\
\text { ballooning }\end{array}$ & 1.573 & 0.764 & 0.05 \\
$\begin{array}{l}\text { Age } \\
\text { Age } \times\end{array} \quad 0.264$ & 0.097 & 0.01 \\
$\quad \begin{array}{l}\text { amyloidosis } \\
\text { ballooning }\end{array}$ & 0.140 & 0.061 & 0.025 \\
\hline
\end{tabular}

The failure to find a significant association between hypertension and heart failure in the elderly patients in this study may appear surprising, Kannel (1974) having shown it to be an important aetiological factor in middle life. However, the present analysis relied on blood pressure measurements during the patients' final admission. These may, however, have been lower than previous levels, falls in blood pressure having been shown both in populations and in individual cases with advancing age or with progression of vascular disease in the hypertensive subject (Miall and Lovell, 1967; Pickering, 1965). Furthermore, an association was found of lower blood pressures with heart failure which suggests that heart failure itself or the drugs given in its treatment may have themselves lowered the blood pressure so as further to obscure any possible aetiological relationship between hypertension and heart failure.

In the case of atrial fibrillation, age, ischaemic

TABLE 4. Distribution of pathological findings in patients with and without atrial fibrillation

\begin{tabular}{lcc}
\hline Factor present & $\begin{array}{c}\text { Patients with failure } \\
\text { number }(\%)\end{array}$ & $\begin{array}{c}\text { Patients without } \\
\text { number }(\%)\end{array}$ \\
\hline None & $5(13 \cdot 5)$ & $58(43 \cdot 5)$ \\
Ischaemic heart disease (IHD) & $9(24 \cdot 3)$ & $41(30 \cdot 6)$ \\
Cardiac amyloidosis (CA) & $11(29 \cdot 7)$ & $19(14 \cdot 2)$ \\
Mitral ballooning (MB) & $0(0)$ & $7(5 \cdot 2)$ \\
IHD+CA & $6(16 \cdot 2)$ & $7(5 \cdot 2)$ \\
CA+ MB & $2(5 \cdot 4)$ & $1(0 \cdot 75)$ \\
IHB+ MB & $4(10 \cdot 8)$ & $1(0 \cdot 75)$ \\
Total & 37 & 134 \\
\hline
\end{tabular}


heart disease, cardiac amyloidosis and mitral valve ballooning ('floppy valve') are shown to be the dominant factors in aged patients. All these are recognized factors (Davies, 1976) but the additive and interaction effects have not been shown hitherto. It is not easy to account for the interaction between age and amyloidosis, i.e. that age only correlates with atrial fibrillation when amyloidosis is absent whilst amyloidosis appears to have a stronger independent action. Davies and Pomerance (1972) have shown that age is associated with a decrease in the amount of muscle in the sino-atrial node and internodal tracts which offers a pathological basis for an age effect in atrial fibrillation but leaves the interaction with amyloidosis unexplained. One could speculate that age and cardiac amyloidosis could both correlate with some third factor which had a more direct causal relationship to atrial fibrillation. Then age might contribute no extra information given that the stronger marker, cardiac amyloidosis, were present. Alternatively, amyloidosis might protect sino-atrial node and tracts from age associated atrophy in some way.

In contrast, the interaction between ischaemic heart disease and mitral valve ballooning in atrial fibrillation is multiplicative, the factor having no effect in isolation but having a powerful combined effect. There is no obvious explanation as to why they should behave in this way rather than have simple additive effects like the factors in heart failure and the remaining factor combinations in atrial fibrillation.

\section{Acknowledgment}

This study was supported by the British Heart Foundation.

\section{References}

CAIRD, F.I. (1976) Valvular heart disease. In: Cardiology of Old Age (Ed. by Caird, F.I., Dall, J.L.C. \& Kennedy, R.C.) p. 231. Plenum Press, New York, London.

DAvies, M.J. (1976) Pathology of the conducting system. In: Cardiology of Old Age (Ed. by Caird, F.I., Dall, J.L.C. \& Kennedy, R.C.) p. 57. Plenum Press, New York, London.

Davies, M.J. \& Pomerance, A. (1972) Quantitative study of ageing changes in the human sino-atrial node and internodal tracts. British Heart Journal, 34, 150.

Denham, M.J., Pomerance, A. \& Hodkinson, H.M. (1977) Pathological validation of auscultation of the elderly heart. Postgraduate Medical Journal, 53, 66.

Hodkinson, H.M. \& Pomerance, A. (1977) The clinical significance of senile cardiac amyloidosis: a prospective clinico-pathological study. Quarterly Journal of Medicine, 46, 381.

Hodkinson, I., Pomerance, A. \& Hodkinson, H.M. (1979) Heart size in the elderly: a clinico-pathological study. Journaliof the Royal Society of Medicine, 72, 13.

KANNEL, W.B. (1974) Role of blood pressure in cardiovascular morbidity and mortality. Progress in Cardiovascular Disease, $27,5$.

Miall, W.E. \& Lovell, H.G. (1967) Relation between change of blood pressure and age. British Medical Journal, 2,660 .

NELDER, J.A. (1975) GLIM (Generalized linear interactiv8 modelling). Applied Statistics, 24, 259.

Pickering, G. (1965) Hyperpiesis: high blood pressure without evident cause: essential hypertension. British Medical Journal, 2, 1021.

Pomerance, A. (1965) Pathology of the heart with and without cardiac failure in the elderly. British Heart Journal, 27, 697. 